\title{
Biomass limit reference points are sensitive to estimation method, timeseries length and stock development
}

van Deurs, Mikael; Brooks, Mollie Elizabeth; Lindegren, Martin ; Henriksen, Ole; Rindorf, Anna

\section{Published in:}

Fish and Fisheries

Link to article, DOI:

10.1111/faf.12503

Publication date:

2021

Document Version

Peer reviewed version

Link back to DTU Orbit

Citation (APA):

van Deurs, M., Brooks, M. E., Lindegren, M., Henriksen, O., \& Rindorf, A. (2021). Biomass limit reference points are sensitive to estimation method, timeseries length and stock development. Fish and Fisheries, 22(1), 18-30. https://doi.org/10.1111/faf.12503

\section{General rights}

Copyright and moral rights for the publications made accessible in the public portal are retained by the authors and/or other copyright owners and it is a condition of accessing publications that users recognise and abide by the legal requirements associated with these rights.

- Users may download and print one copy of any publication from the public portal for the purpose of private study or research.

- You may not further distribute the material or use it for any profit-making activity or commercial gain

- You may freely distribute the URL identifying the publication in the public portal 
1 Title: Biomass limit reference points are sensitive to estimation method, time-series length,

2 and stock development

3

4 Running title: Biomass limit reference points

5

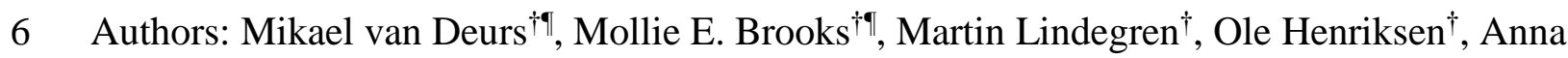
$7 \quad$ Rindorf $^{\dagger}$

8

$9 \quad{ }^{\mathbb{I}}$ Mikael van Deurs and Mollie E. Brooks should be considered joint first author

$11{ }^{\dagger}$ Technical University of Denmark, Institute for Aquatic Resources, Kemitorvet 1, 2800

12 Lyngby, Denmark

13

14 Corresponding author: Mikael van Deurs, Technical University of Denmark, Institute for

15 Aquatic Resources, Kemitorvet 1, 2800 Lyngby, Denmark. E-mail: mvd@aqua.dtu.dk)

16

17 Running title: Biomass limit reference points

18

19 
22 Abstract: Biomass limit reference points are widely used in fisheries management and defines

23 the biomass threshold below which stock productivity (i.e. recruitment) is likely to be

24 impaired. Scientifically sound and transparent methods for estimating biomass thresholds are

25 therefore needed together with ways of quantifying uncertainties. The main focus of the study

26 was placed on two methods currently applied to several small-bodied pelagic species in the

27 Northeast Atlantic. These methods have not formerly been described in the scientific

28 literature and are in the present study being compared to some already described methods, of

29 which, one is broadly applied outside the Northeast Atlantic. Using a combination of data

30 simulations and data from 51 small-bodied pelagic fish stocks, we analyzed the sensitivity of

31 estimated biomass thresholds to (i) the choice of method, (ii) time-series length, and (iii)

32 stock development (e.g. rebuilding or declining). It was demonstrated that estimated biomass

33 thresholds are associated with considerable uncertainty not previously quantified.

34 Furthermore, the level of the estimated threshold and the amount of uncertainty depended on

35 choice of method, time-series length, and stock development trends. Hence, this study

36 contributes to improving the quality of future biomass limit reference points by providing

37 guidance regarding choice of method and how to demonstrate stock-specific uncertainties.

39 Key words: Fisheries management, stock-recruitment, statistical uncertainty, small pelagics,

40 RAM Legacy, sustainable exploitation

43 Table of content:

44 1. Introduction 
46 2.1. Methods for estimating biomass thresholds

$47 \quad 2.2$. Simulation study

$48 \quad$ 2.3. Data-driven study

49 2.3.1. Stock assessment data

$50 \quad$ 2.3.2. Comparisons of methods

51 2.3.3. Effects of time-series length and stock development

52 2.3.4. Analysis of case-study stocks

53 3. Results

$54 \quad$ 3.1. Simulation study

55 3.2. Data-driven analysis

$56 \quad 3.2 .1$. Comparison of methods

57 3.2.2. Effects of time-series length and stock development

$58 \quad$ 3.2.3. Case study stocks

59 4. Discussion

60

61

62

63 1. Introduction 
64 Fisheries management worldwide uses a variety of biomass limit reference points to ensure a sustainable exploitation of fish stocks (Foley et al. 2015). Biomass limit reference points based on stock-recruitment (SR) relationships originate from the expectation that when the biomass of mature and reproducing individuals (i.e. spawners) falls below a certain biomass threshold (BT), recruitment and stock productivity is impaired and the risk of stock collapse increases (e.g. Sissenwine \& Shepherd, 1987; Mace, 1994; Nakatsuka et al., 2017). This assumption is supported by the observation that many stocks, which have experienced low spawning stock biomass also suffered from poor recruitment (Myers et al., 1994; Barrowman \& Myers, 1999).

BTs based on SR relationships, in one or the other way, are particularly important for management of small-bodied pelagic species. Maximum sustainable yield of these species is often attained using either the so-called "escapement-strategy", where the management objective is to maintain a fishing pressure resulting in a low probability that spawning stock biomass will fall to a level where recruitment is impaired (i.e. below BT), or harvest control rules, where so-called "biomass triggers" guide shifts in fishing pressure to avoid impaired recruitment (Deroba \& Bence, 2008; Gjøsæter et al., 2014, Pikitch, 2015). While it is often assumed that maintaining a fishing pressure capable of providing F $_{\text {MSY (i.e. the fishing }}$ mortality resulting in maximum sustainable yield) does not place recruitment at risk, this is not necessarily the case for small-bodied pelagic species. It has, for example, been shown that F $_{\text {MSY }}$ is either above or close to the fishing mortality leading to a 5\% risk of impaired recruitment in three out of four clupeids stocks in the North Sea and Baltic Sea (Rindorf et al., 2017).

The SR relationship is often weak, and for the majority of stocks, there is either no apparent "best" relationship or the parameters of the selected functional SR model is highly time varying (Ricard et al., 2012, Subbey et al., 2014; Szuwalski et al., 2015; Szuwalski et al., 

nonparametric (or semi-parametric) methods for estimating BTs have been suggested.

Presently, in particular, two types of approaches are applied to stocks in the Northeast

92 Atlantic region by the International Council for the Exploration of the Sea (ICES): (i) a nonparametric approach where BT is equal to "the lowest spawning stock biomass where large recruitment is observed" (with no strict default definition of "large recruitment") and (ii) a simple parametric approach, where BT is equal to the spawning stock biomass at the breakpoint in a segmented regression (i.e. a hockey stick model) fitted to the SR data (ICES, 2017). These methods have not formerly been described in the scientific literature, but documentation can be found in ICES (2017).

In contrast to the above methods, alternative semi-parametric approaches, relying on assumptions about the underlying functional SR relationship, have previously been suggested in the literature. Examples of such approaches are those where BT is equal to the spawning stock biomass producing 50\% of maximum recruitment predicted by a Ricker or BevertonHolt model (Ricker, 1954; Myers et al., 1994; Beverton \& Holt, 1957).

In the case of the approaches used by ICES in the Northeast Atlantic for small pelagics, simple assumptions about the SR relationship are used to derive BT, in relation to which, a target fishing mortality is set to ensure that BT is avoided with a high probability (ICES, 2014). However, in other parts of the world, models of the SR relationship is used directly in the estimation of the target fishing mortality, while the biomass limit reference points are set based on a certain percentage of the expected stock biomass when fishing is absent (i.e. virgin biomass or $\mathrm{B}_{0}$ ). Lower biomass limits are commonly defined as 0.20 times $\mathrm{B}_{0}$ and target limits as 0.40 - 0.60 times $\mathrm{B}_{0}$ (AFMA, 2007; Pikitch et al., 2012). The consistency between this approach and the approaches used for Northeast Atlantic stocks is unknown. 
113 Besides choice of method, numerous other aspects may influence BT estimates. These could

114 be the length of the time-series used to estimate BT. Time-series length varies between

115 assessments and increases over time as more data is being added. Furthermore, the time-

116 series used when assigning reference points are occasionally shortened if regime-shifts have

117 taken place, or if quality issues are raised in relation to historical landings. Finally, stocks that

118 are depleting or rebuilding (i.e. demonstrating declining or increasing spawning biomass over

119 time) may pose additional challenges (i.e. Szuwalski et al., 2019), since the range of observed

120 biomasses expands as time-series length increases, potentially changing the perceived SR

121 relationship over time. Currently, we know of no published systematic study evaluating the

122 confounding effects and biases of BTs arising from these factors. Hence, experts confronted

123 with the task of assigning BTs to stocks are left with little guidance.

124 To overcome this issue and provide guidance for the estimation and use of BTs, the objective

125 of the present study was to assess BT uncertainty. The sensitivity of BT estimates to (i)

126 choice of method, (ii) time-series length, and (iii) stock development was analyzed and new

127 R code to estimate the bias and precision of the BT estimates was developed. The first part of

128 the study used simulated SR data. However, to demonstrate that conclusions derived from

129 simulations are relevant in a practical setting, we supplemented these with analyses of real

130 SR data sets from 51 small-bodied pelagic fish stocks.

2. Materials and Methods

134 The main focus of the study was placed on the methods currently applied to several smallbodied pelagic species in the Northeast Atlantic, which has not formerly been described in

136 the scientific literature. However, for comparison, we also included previously described 
137 methods; including one method, which is broadly applied outside the Northeast Atlantic

138 (Pikitch et al., 2012; AFMA, 2007).

139 Altogether we considered six different methods: two nonparametric methods based on

140 percentiles (ICES, 2017), one parametric approach based on a simple hockey stick SR

141 relationship (ICES, 2017), two parametric methods based on estimated SR curves (Myers et

142 al., 1994; Beverton \& Holt, 1957), and one semi-parametric approach based on a fixed

143 proportion of $\mathrm{B}_{0}$ (Myers, 1999).

144 The two nonparametric methods defined BT as the lowest observed spawning stock biomass

145 producing a "large" recruitment (type 1 in the ICES guidelines (ICES, 2017)). Here, we used

146 two definitions of "large": recruitment $>$ 50th percentile and recruitment $>80$ th percentile

147 (respectively referred to as P0.5 and P0.8 hereafter).

148 In the parametric hockey stick method (HS) (type 2 in ICES (2017)), BT was defined as the

149 breakpoint of a segmented regression. The breakpoint was estimated using the grid-search

150 method recommended in Borrowman \& Myers (2000). This method is referred to as HS in

151 the following.

152 The two parametric methods, which involved model fitting of Beverton-Holt (Beverton \&

153 Holt, 1957) and Ricker (Ricker, 1954) relationships, relied on the assumption that BT is equal

154 to a certain percentage of the spawning stock biomass that produces maximum recruitment as

155 predicted by the SR model, with the added requirement that the BT cannot be larger than the

156 maximum observed spawning stock biomass (Myers et al., 1994). Myers et al. (1994) used

$15750 \%$ of the maximum predicted recruitment, but initial investigations (in preparation for the

158 present study) showed that $50 \%$ resulted in BTs systematically lower than the minimum

159 spawning stock biomass of the simulated datasets for the Ricker model. Therefore, to ensure

160 that all BTs were targeting the same point of the SR curve, rather than using the (arbitrary) 
161 choice of $50 \%$ of maximum recruitment, we used the percentage that maximized the probability of identifying the breakpoint from a hockey stick. The resulting percentages were $83 \%$ and $51 \%$ for the Ricker and Beverton-Holt, respectively. These two methods are

164 hereafter referred to as RK83 and BH51, respectively. Beverton-Holt and Ricker curves were

165 fitted using maximum likelihood estimation via Template Model Builder (TMB) assuming

166 log-normal distributed residuals (Kristensen et al., 2015).

167 In relation to the semi-parametric approach where BT was equal to a fixed proportion of $\mathrm{B}_{0}$, 168 we used $20 \%$ as the fixed proportion and used the maximum observed spawning biomass

$169\left(\mathrm{~B}_{\max }\right)$ as a simply proxy for $\mathrm{B}_{0}$. We will hereafter refer to this approach as $0.2 \mathrm{~B}_{\max }$.

170 Summary and illustrations of methods are provided in figure 1.

$172 \quad$ 2.2. Simulation study

173 In order to simulate SR data with a common underlying threshold, we simulated from a 174 hockey stick relationship (i.e. simulated threshold = breakpoint of hockey stick). The hockey 175 stick in all our simulations had a breakpoint and asymptote at $(100,100)$, corresponding to a 176 simulated threshold of 100 . In the default simulations, data sets were simulated from a 177 hockey stick with $\mathrm{n}=10,20,30$, or 40 spawning stock biomasses (i.e. mimicking time-series 178 lengths of $10,20,30$, or 40 years) drawn from a uniform distribution ranging from 40 to $179200 \%$ of the breakpoint. For each spawning stock biomass, recruitment was simulated from a 180 log-normal distribution around the hockey stick. A recruitment coefficient of variation (CV) 181 of 0.63 was used for the default simulations, corresponding to the median $\mathrm{CV}$ in the real 182 stock data described in the subsequent section. In the same way, we also based the beforementioned spawning stock range on the real stock data (to which we fitted hockey stick models to derive the median range). The default spawning stock biomass range from 40 to 
$185200 \%$ of the breakpoint corresponded to a steepness of 0.4 . Steepness is defined as the 186 predicted recruitment (in this case based on a hockey stick) at $20 \%$ of $\mathrm{B}_{\max }$ divided by the

187 predicted recruitment at $\mathrm{B}_{\max }$ (e.g. Mace \& Doonan, 1988; Myers et al., 1999; Mangel et al., 188 2013). A total of one thousand replicated SR data sets were simulated for each sample size $189(\mathrm{n}=10,20,30$, and 40$)$. It was not considered meaningful to apply the $0.2 \mathrm{~B}_{\max }$ approach to the 190 simulated SR data sets because $\mathrm{B}_{\max }$ is tightly linked to the range of spawning biomasses 191 used in the simulations.

192 The sensitivity of the results to each simulation setting were carefully investigated. Firstly, 193 the effect of the recruitment CV, was tested by re-running the simulations using the 5 and 95

194 percentiles of the $\mathrm{CVs}$ found in the real stock data $(\mathrm{CV}=0.18$ and 1.23 , respectively).

195 Illustrations of what the simulated data looks like under different assumptions about the 196 recruitment CV can be found in the supplementary materials.

197 The sensitivity of the results to erroneous assumptions regarding the underlying SR processes 198 was investigated by simulating SR data from different underlying curves (i.e. not just a strict 199 hockey stick assumption as used in the default simulations). In order to do this, we fitted 200 Ricker and Beverton-Holt curves to simulated hockey stick data with low variance $(\mathrm{CV}=$ 201 0.01) and a large sample size $(n=1000)$ with the same range of spawning stock biomasses as 202 in the default simulations. The rest of the calculations were performed as described above for 203 HS, except this time we used the fitted Beverton-Holt and Ricker curves to simulate 204 recruitment, instead of the hockey stick.

205 Lastly, we were re-running simulations with spawning stock range from 40 to $300 \%$ of the 206 breakpoint and 40 to $400 \%$ of the break point, which effectively increase steepness to 0.6 and 2070.8 , respectively (since $\mathrm{B}_{\max }$ increase). 
208 Potential effects of stock development (rebuilding or declining) were investigated by sorting

209 each of the 1000 replicate SR data sets $(n=40)$ from highest to lowest spawning stock

210 biomass. We then drew sub-samples of $n=20,25,30$, and 35 from either end of the sorted SR

211 data (i.e. from the high end when imitating declining stocks and from the low end when

212 imitating rebuilding stocks). This approach ensured that depleting stocks initially had no or

213 few data below the breakpoint, whereas rebuilding stocks initially had relatively few data

214 above the breakpoint. BT was calculated using P0.5, P0.8, HS, RK83, and BH51 for each of

215 one thousand replicate sub-sampled data sets of each sample size.

216 All code used to simulate data and estimate BTs and the associated uncertainty is available at

217 https://github.com/mebrooks/StockRecruit.

2.3. Data-driven study

\subsubsection{Stock assessment data}

221 We compiled time-series of spawning stock biomass and recruitment of 51 small-bodied

222 pelagic stocks with more than 10 years of data from the RAM (Ransom A. Myers) Legacy

223 Stock Assessment Database (Version 4.44-assessment-only. Released 2018-12-22. Accessed

224 [Date accessed 2017-18-08]. Retrieved from DOI:10.5281/zenodo.2542919) (Ricard et al.,

225 2012) and the ICES database (extracted using ICES tools: https://github.com/ices-tools-

226 prod/icesSAG, accessed 2018-09-06 using the getSAG function in recruitment (recruitment

227 package: icesSAG)) (ICES, 2018). In order to avoid stock data from the Ram Legacy data

228 base originating from stock assessment models with build-in SR models, only stocks used in

229 Britten et al. (2016) were included. The compilation of stocks had a global coverage and the

230 following families were represented: Clupeidae, Scombridae, Gadidae, Hexagrammidae,

231 Ammodytidae, Engraulidae, Osmeridae, and Carangidae. The average number of years in 
each time-series was 35, but seven stocks had less than 20 years of data. The longest timeseries was 79 years. If the same stock was recorded in both the RAM and ICES database, the ICES data was selected. A detailed overview of the stocks is provided in the supplementary material.

To allow comparisons of BT estimates across stocks, we expressed BT relative to the geometric mean spawning stock biomass of each stock.

240 The precision of BTs resulting from the HS method was assessed by bootstrapping the CV of

241 the breakpoint $\left(\mathrm{CV}_{\mathrm{HS}}\right)$ (i.e. estimating the uncertainty of the breakpoint estimate). The

242 bootstrap procedure was organized in three steps: (i) re-sample paired observations with

243 replacement 1000 times from the SR time-series to obtain the same number of observations

244 as in the original dataset, (ii) estimate BT for each of the re-sampled data sets, and (iii)

245 calculate the $\mathrm{CV}_{\mathrm{HS}}$ across the re-sampled data sets. The R-code for this is available in the

246 function bootBlim() at https://github.com/mebrooks/StockRecruit.

247 In the data-driven part of the study, we only focused on BT approaches that are currently 248 applied in fish stock assessment and management (i.e. P0.5, P0.8, HS, and $0.2 \mathrm{~B}_{\max }$ ). It was

249 not considered meaningful to include RH83 and BH51, mainly since these were adapted

250 specifically to the simulated data; without applied cases available to guide the choice of 251 realistic percentages (i.e. different from $83 \%$ and $51 \%$ ). 
254 In order to test the sensitivity of BTs to time-series length and stock development in real data, we performed the following three steps: (i) from each stock a subset comprised of the first 10 years $(n=10)$ of stock-recruitment pairs was selected (i.e. representing a historic perspective when only 10 years of data were available and the first assessment of the stock was carried out). (ii) HS, P0.5, and P0.8 BTs were estimated, and (iii) data subsets were sequentially prolonged by adding one year $(n=11,12, \ldots, 40)$. These three steps were repeated for each $n$. BT was scaled to the geometric mean spawning stock biomass of the whole time-series. Subsequently, we calculated the slope of BT as a function of $\mathrm{n}$ (hereafter referred to as BTslope). A positive BT-slope indicates that BT increases with increasing time-series length. To determine if the relationship between time-series length and BT was influenced by stock development, we also calculated the slope of the spawning stock biomass as a function of time (S-slope). A positive S-slope indicates rebuilding stock and negative slope indicates declining stock. All slopes were calculated using linear regression. S-slopes were plotted against BT-slopes to reveal any relationships.

Four stocks were selected as our case-studies. The selected stocks all had at least 38 years of data, only minor temporal trends in spawning stock biomass, and represented different types of SR relationships based on visual inspection: (i) Peruvian anchoveta (Engraulis ringens,

273 Engraulidae) from North Central Peru (approaching an ever-increasing SR relationship, 274 recruitment $\mathrm{CV}=0.35$ and $\mathrm{CV}_{\mathrm{HS}}=0.52$ ), (ii) Pacific herring from the central coast (Clupea 275 pallasii, Clupeidae) (occasional very large recruitment, recruitment $\mathrm{CV}=0.98$ and $\mathrm{CV}_{\mathrm{HS}}=$ 276 0.47), (iii) Chub mackerel from Tsushima strait (Scomber japonicas, Scombridae) (hockey stick or Ricker-like SR relationship, recruitment $\mathrm{CV}=0.3, \mathrm{CV}_{\mathrm{HS}}=0.20$ ), and (iv) Pacific 
278 herring from the prince Rupert district C. pallasii (no clear stock-recruitment relationship,

279 recruitment $\left.\mathrm{CV}=0.66, \mathrm{CV}_{\mathrm{HS}}=0.49\right)$.

280 For each stock we evaluated estimation uncertainty and examined the effect of increasing the

281 time-series length. This was done using the following three steps: (i) $n$ pairs of spawning

282 stock biomass and recruitment were randomly sampled with replacement 100 times, (ii) BT

283 was estimated for each of the one hundred datasets (using either P0.5, P0.8, or HS), and (iii)

284 the above steps were repeated with $n=10,11,12, \ldots, 38$ (i.e. representing different time-

285 series lengths).

286

287

288

3. Results

289

3.1. Simulation study

290 Estimation bias (estimated BT relative to the simulated biomass threshold) and precision

291 (width of confidence intervals) were affected by time-series length and choice of method. In

292 general, the nonparametric methods produced more precise BT estimates compared to the parametric methods (Fig. 2), but both P0.5 and P0.8 were negatively biased with the bias being greatest for P0.5 (Fig. 2). Precision increased with increasing time-series length, but due to the bias of P0.5, the confidence intervals of long time-series did not include the

296 simulated threshold. P0.8 produced slightly less precise estimates of BT and, in spite of being

297 consistently negatively biased, retained the simulated threshold within the confidence interval 298 at all time-series lengths (Fig. 2).

299 Two of the parametric methods (HS and BH51) resulted in BTs that were unbiased regardless

300 of time-series length and recruitment CV. The third parametric method, RK83, was positively 301 biased, but bias decreased as time-series length increased. Confidence intervals around BH51 
estimates were very large. Among the parametric methods, HS was the most precise and un-

biased method, with lower confidence limits similar to those derived using the nonparametric methods but larger upper confidence intervals.

The precision of the different methods was highly dependent on the variation in recruitment around the SR curve. When the recruitment $\mathrm{CV}$ was low, $\mathrm{HS}$ was superior to all other methods, having no bias and high precision (Fig. 2 left panel). As CV increased, the nonparametric methods became increasingly biased, but retained approximately the same precision, whereas the precision of the parametric methods decreased substantially. While HS remained unbiased at all levels of recruitment $\mathrm{CV}$, the $\mathrm{HS}$ confidence intervals ranged from -

31150 to $+100 \%$ at the highest recruitment $\mathrm{CV}$ (Fig. 2). BH51 always had lower precision than

312 the remaining parametric methods while RK83 either had lower precision (Fig. 2 left panel)

313 or positive bias (Fig. 2 middle and right panels). Both the nonparametric (P0.05 and P0.8)

314 and the parametric methods (HS, BH51, and RK83) were relatively insensitive to the 315 assumption made about the shape of the underlying SR relationship and steepness, except

316 that precision declined for all methods when steepness increased from 0.4 to 0.8 (see

317 supplementary material).

318 When simulating a depleting stock, $\mathrm{P} 0.5$ and P0.8 decreased rapidly as time-series length

319 increased (Fig. 3), passing from positive to negative bias. HS changed from positive bias to

320 unbiased for longer time-series. For rebuilding stocks, P0.5 and P0.8 showed consistent

321 negative bias of around 50\% and 25\% respectively, while HS was relatively unbiased. There

322 was no substantial change in the bias of rebuilding stocks with time-series length.

324 3.2. Data-driven analysis

325 3.2.1. Comparison of methods 
326 When comparing different methods (P0.5, P0.8, HS, and $\left.0.2 \mathrm{~B}_{\max }\right)$ several patterns emerged.

327 BTs from P0.5 were always equal to or lower than those produced by HS (Fig. 4a). For the

328 vast majority of stocks, $\mathrm{P} 0.5, \mathrm{P} 0.8$, and $0.2 \mathrm{~B}_{\max }$ produced $\mathrm{BTs}$ equal to or less than the

329 geometric mean spawning stock, whereas, HS produced BTs above the geometric mean

330 spawning stock for $42 \%$ of the stocks. For stocks where HS produced BTs that were less than

331 half of the geometric mean spawning stock biomass, agreement between HS and P0.5 was

332 relatively high (Fig. 4a). In contrast, there was no agreement between P0.5 and HS for stocks

333 where HS produced BTs higher than the geometric mean spawning stock biomass. When

$334 \mathrm{CV}_{\mathrm{HS}}$ was above 0.3 (i.e. breakpoint estimate from HS was highly uncertain), BTs from P0.5

335 were equal to or less than half the geometric mean spawning stock biomass. The agreement

336 between P0.8 and HS was in general higher when $\mathrm{CV}_{\mathrm{HS}}$ was below 0.3 (Fig. 4b), while the

337 agreement between P0.8 and P0.5 was high for some stocks and low for others (Fig. 4c).

$3380.2 \mathrm{~B}_{\max }$ were generally showing poor agreement with all other methods and the relationship

339 between BTs from the nonparametric methods (P0.5 and $\mathrm{P} 0.8$ ) and $0.2 \mathrm{~B}_{\max }$ tended to be

340 negative (i.e. the higher the BT from P0.5 the lower the BT from 0.2B $\mathrm{max}_{\text {) }}$ (Fig. $4 \mathrm{~d}-\mathrm{f}$ ).

341 BTs more than twice the geometric mean spawning stock biomass were observed for $0 \%$,

$3424 \%, 8 \%$, and $4 \%$ of the stocks, when using P0.05, P0.8, HS, and $0.2 \mathrm{~B}_{\max }$, respectively. The

343 overall patterns depicted in figure 4 were similar to those seen in the simulated data (see

344 supplementary material). We also examined effects of the recruitment CV (i.e variation in

345 recruitment when above the hockey stick breakpoint), but no clear patterns emerged (see

346 supplementary material). With regards to steepness, the median BT from HS was equal to

$34733 \%$ of $\mathrm{B}_{\max }$ and $20 \%$ of the BTs from HS were $>60 \%$ of $\mathrm{B}_{\max }$ (i.e. low steepness), whereas

$34831 \%$ were below $20 \%$ of $\mathrm{B}_{\max }$ (i.e. high steepness). 
351 The stocks represented a range of different developmental trajectories, from depleting

352 (negative S-slopes) to rebuilding (positive S-slopes) (Fig. 5). When using P0.5, P0.8, and HS, 353 negative S-slopes were mainly associated with negative BT-slopes, although, there were

354 instances where negative S-slopes were associated with positive BT-slopes when using HS.

355 In contrast, when using $0.2 \mathrm{~B}_{\max }$, negative $\mathrm{S}$-slopes resulted mainly in neutral BT-slopes.

356 Positive S-slopes yielded mainly positive BT-slopes for HS, P0.8, and $0.2 \mathrm{~B}_{\max }$, whereas, for

357 P0.5, positive S-slopes was mainly associated with neutral BT-slopes (i.e. slopes close to 358 zero).

361 P0.5 and P0.8 decreased with increasing time-series length for all four stocks, and concurrently the precision decreased (i.e. confidence intervals narrowed, Fig. 6). The anchovy stock, which appeared to have a continuously increasing SR relationship, showed low precision (i.e. large standard deviations) when applying HS, higher precision for P0.8, and very high precision for P0.5 (Fig. 6). The discrepancy between P0.5 and HS was largest for this stock. For the remaining stocks, the precision of P0.8 and HS was more similar. The precision of P0.5 varied considerably among stocks, being lowest for the two herring stocks for some stocks, but not for others (Fig. 6). In general, the precision of HS was relatively low and improved only slightly with longer time-series, which was in particular pronounced for the stock where the SR relationship was ever-increasing (anchovy). 
376 Biomass limit reference points, building on the idea that recruitment is impaired when stock

377 biomass drops below a certain critical biomass threshold (BT), are an essential part of

378 fisheries management and knowledge of the uncertainties associated with a given BT estimate are key to providing robust management advice (Haltuch et al., 2008). This study evaluated several methods for estimating BT for small-bodied pelagic species, primarily

381 focusing on three methods applied in the North Atlantic (HS, P0.5, and P0.8). However, for 382 comparison, a number of alternative methods used in other parts of the world, or described in 383 the literature, were included as well (BH51, RK83, and $\left.0.2 \mathrm{~B}_{\max }\right)$.

384 First of all, the present study demonstrated that estimates of BT are associated with considerable uncertainty. Precision (i.e. measured as deviation from the simulated threshold) and bias (i.e. as measured by width of confidence intervals) depended on the choice of method, year-to-year variation in recruitment, time-series length, and stock development. In general, the simulations and the data-driven studies were consistent regarding the overall conclusions. Furthermore, four case-studies illustrated the degree of inter-stock variability, supporting the notion that stock-specific decisions may always be needed (Katsukawa, 2004).

391 When variation in recruitment was low, the hockey stick approach (HS) was both unbiased and precise regardless of time-series length. HS generally provided unbiased BT estimates in

393 the simulations, and was relatively insensitive to trends in stock development. For depleting

394 stocks, HS decreased as stock size was depleted and approached the simulated threshold,

395 leading to the elimination of an initial positive bias but not resulting in any negative bias. A 396 similar trend was seen in real data when the time-series length was less than 20 years. 
397 However, precision tended to be relatively low, when variation in recruitment was low, which was also evident from the four case studies.

399 The nonparametric methods defining "large" recruitment as greater than the 50th percentile

400 (P0.5) or the 80th percentile (P0.8) provided relatively precise estimates of the simulated 401 threshold in both the simulation study and the four case-studies, in particular for P0.5.

402 Considering that P0.5 was by far the most precise of the methods tested, using this methods and adding a fixed percentage as a buffer may seem as an appealing approach. However, these nonparametric methods were also prone to systematic underestimation of the simulated threshold (in the simulation study) and when analyzing real data, P0.5 yielded BTs that were, on average, roughly half of those from HS. Lastly, when recruitment variation was increased in the simulation study, estimated BT decreased further. This pattern was, however, mainly confined to the simulation study and did not show up in the analyses of real stock data (see supplementary materials).

410 The percentage providing results comparable with HS for Beverton-Holt (51\%, BH51) was

411 virtually identical to the 50\% suggested by Myers et al. (1994). However, BH51 was also the

412 most imprecise of the methods. Presumably because the maximum recruitment was poorly

413 estimated by the Beverton-Holt curve. In relation to the Ricker approach, the percentage of

414 maximum recruitment providing results comparable with HS was 83\% (RK83),

415 demonstrating that using 50\%, as suggested by Myers et al. (1994), would have resulted in a 416 systematic underestimation of the simulated threshold. Hence, the method relies heavily on 417 the ability to identify an appropriate percentage. Another limitation of this methods is the low 418 precision in cases where recruitment variation is high (similar to HS and BH51) (see also 419 Szuwalski et al., 2019). Lastly, BH51 and RK83 is based on relatively strict assumptions 420 (that cannot be easily tested) about the underlying functional SR relationship. 
421 Besides the fact that $0.2 \mathrm{~B}_{\max }$ was based on an arbitrary choice (in this case $20 \%$ of $\mathrm{B}_{\max }$ ) it is

422 also hinged on the assumption that the "virgin" (or unfished) stock biomass is known.

423 Furthermore, the present study revealed a very low agreement with other methods analyzed

424 in the present study, which is worrying (i.e. as seen in Fig. 4). Small pelagic fishes generally

425 exhibit increases in recruitment over a greater range of spawning biomass than gadids and

426 pleuronectid and hence attain a lower proportion of the maximum recruitment on average at $42720 \%$ of $B_{\max }$ (i.e. lower steepness (Mace and Doonan, 1988; Myers et al., 1999)). This may

428 explain some of the systematic differences between this methods and those considering both 429 spawning stock biomass and recruitment.

430 One approach to selecting appropriate biomass limit reference points, could be to combine several methods and consider agreements/disagreements among methods. In general there was surprisingly little agreement between methods (i.e. as seen in Fig. 4). There was, however, relatively high consistency between P0.5 and HS when the HS-estimated BTs were

434 less than the geometric mean spawning stock biomass. However, for stocks where the HS435 estimated BTs were greater than the geometric mean spawning stock biomass, the BTs from the different methods were unrelated. P0.8 and HS produced similar ranges of BTs when averaging across stocks, but at the level of the individual stock, P0.8 and HS yielded very different results. This was also evident from the case studies, where $\mathrm{P} 0.8$ provided the highest value for the Prince Rupert district herring stock, whereas, for the anchovy stock, the highest 440 value was derived from HS.

441 To gain acceptance and credibility of agreed biomass limit reference points, not only among 442 scientists, but also among managers and end-users (Caddy \& Seijo, 2005; Rice, 2005), robust 443 and transparent approaches to estimate, evaluate, and explain the associated uncertainty of 444 are needed. Our assessment and comparison of BT methods serve to formally illustrate several previously unstudied and unquantified sources of biases associated with the 
446 estimation of BTs. In addition, it shows that our ability to identify a simulated threshold is

447 rather limited based on the current set of methods applied by fisheries scientists in the

448 northeast Atlantic (ICES, 2017). The primary limitation and source of uncertainty arises from

449 one of the most well studied, yet still insufficiently understood process in fisheries science,

450 namely our ability to reliably represent and characterize SR relationships (Szuwalski et al.,

451 2015). The approaches tested within this study perform well (i.e. in terms of precision and

452 accuracy) when recruitment variation was low. However, this is seldom the case for marine

453 fish stocks that typically demonstrate highly variable and potentially non-stationary SR

454 relationships (Lindegren \& Eero 2013; Beggs et al., 2014). Such high variability is

455 particularly prevalent in short-lived, fast growing and early maturing species of small pelagic

456 fish (e.g. MacKenzie \& Köster, 2004; Lindegren \& Checkley, 2013; Szuwalski et al., 2019).

457 To overcome these challenges, a better understanding of the sources of variation in

458 recruitment is needed to appropriately account for these underlying mechanisms in SR

459 models and ultimately in relation to biomass limit reference points.

460 One of the most frequently invoked sources of variability in stock abundances and/or

461 recruitment, besides density-dependence, is the underlying variability in climate or system

462 productivity (i.e. carrying capacity) that ultimately determines investment in reproduction,

463 fecundity, early-life survival and consequently recruitment success (e.g. Brunel \& Boucher

464 2006; MacKenzie et al., 2012; Sparrevohn et al., 2013; Bartolino et al., 2014; Hobday et al.,

465 2016; Tommasi et al., 2017; Payne et al., 2019). Although meta-analyses of environmental

466 correlates and predictors of recruitment show a common tendency for published recruitment-

467 environment correlations to fail when verified with new data (Myers, 1998), more recent

468 examples show that environmental predictors of recruitment of small pelagic fish may hold

469 upon retesting (Lindegren \& Checkley, 2013; Lindegren et al., 2017). Hence, identifying and

470 introducing ecologically underpinned predictors of recruitment variability into methods for 
assigning reference points could be one way to proceed. In addition to the potential

472

473

474

475

476

477

478

480

481

482

483

484

485

486

487

488

489

490

491

492

493

494

495

consideration and inclusion of environmental predictors, new techniques to assign reference

points are needed. Recent developments of nonparametric models allowing for estimations of reference points, while accounting for model uncertainty seem promising in this regard (e.g. Cadigan, 2012) and should be formally tested and considered as part of the toolbox needed for fisheries scientist and managers to estimate and decide on robust BT within fisheries management.

The estimation of SR relationships and the spawning stock biomass at which recruitment is impaired is a key uncertainty in estimation of not only biomass limit reference points, but also $F_{M S Y}$ (Cadigan, 2012). The two most influential factors are the natural mortality the stock experiences and the steepness of the stock recruitment relationship (i.e. the proportion of the maximum recruitment attained at $0.2 \mathrm{~B}_{\max }$ (Mace, 1994; Forrest et al., 2010; Zhou et al., 2012)). Steepness is easily estimated from HS and hence the code in the supplementary can be used to provide a rapid check of the validity of any assumptions of steepness. In the stocks investigated here, the median HS of $0.33 \mathrm{~B}_{\max }$ corresponded to a median steepness of 0.55 , which is low compared to previous analyses using Ricker models for clupeids and engraulids and scombrids (0.71 and 0.62$)$ but in line with values for scombrids $(0.52)$ (Myers et al., 1994).

Choice of method was the most influential factor in estimating BT. Without clear guidelines for when to choose each of the methods, this introduces inconsistencies, hidden subjectivity and lack of transparency in stock management. Secondly, time-series length was found to be important. Since time-series, displaying clear signs of a regime-shift, are occasionally shortened in real life assessment settings when updating reference points (i.e. including only the most recent part of the time-series), knowing the sources of uncertainty introduced by doing so is essential. Finally, stocks that are depleting or rebuilding (i.e. demonstrating 
496 declining or increasing spawning biomass across years) may pose additional challenges, since

497 the range of observed biomasses expands as time-series length increases, potentially

498 changing the perceived SR relationship over time.

499 When recruitment variation is low, the HS method seem promising. However, as also

500 discussed above, variation in recruitment can be substantial when it comes to small-bodied

501 pelagic fish stocks. Hence, it may be useful to consider other methods in addition to HS.

502 However, further studies will be needed before we can formulate quantitative guidelines as to

503 which combination of methods to use and how and when to use them. Furthermore, as the

504 methods differed in their probability of over- or under-estimating the simulated threshold, the

505 decision on which method is preferable also depends on the risk-averseness of the decision

506 makers and the approach taken by scientists to incorporate the increase in reported

507 uncertainty (Rice, 2005). Lastly, we recommend that in addition to clearly stating the

508 methods used, the amount of data used, trends in the stock development, and the uncertainty

509 of the estimated BT, should be clearly reported as well.

510

511 Acknowledgement:

512 Rodrigo Wiff, David C.M. Miller, and one anonymous reviewer provided constructive

513 critiques on drafts of this manuscript. The study was partly supported by the European

514 Maritime and Fisheries Foundation and the Ministry of Environment and Food of Denmark

515 (grant ID: 33113-B-19-150). AR \& MB also received funding from the PROBYFISH project

516 (EASME/EMFF/2017/022). Thanks to A. Kokkalis for helpful discussion.

518 Data availability: 
519 Important R-code are available at https://github.com/mebrooks/StockRecruit.

520 Stock-recruitment data were downloaded from the open access Ram Legacy Stock

521 Assessment Database (Version 4.44-assessment-only. Released 2018-12-22) (Ricard et al., 522 2012) and the ICES database (extracted using ICES tools: https://github.com/ices-tools-

$523 \mathrm{prod} / \mathrm{icesSAG})$ (ICES, 2018).

528 References

AFMA, Australian Fisheries Management Authority. (2007). Commonwealth Fisheries

530 Harvest Strategy: Policy and Guidelines. Department of Agriculture, Fisheries, and Forestry.

531 Barrowman, N. J., \& Myers, recruitment. A. (2000). Still more spawner-recruitment curves:

532 the hockey stick and its generalizations. Canadian Journal of Fisheries and Aquatic Sciences, 533 57(4), 666-676. https://doi.org/10.1139/f99-282

534 Bartolino, V., Margonski, P., Lindegren, M., Linderholm, H., Cardinale, M., Rayner, D.,

535 Wennhage, H., \& Casini, M. (2014). Forecasting fish stock dynamics under climate change:

536 Baltic herring as a case study. Fisheries Oceanography, 23, 258-269.

537 https://doi.org/10.1111/fog. 12060

538 Beggs, S. E., Cardinale, M., Gowen, R. J., \& Bartolino, V. (2014). Linking cod (Gadus

539 morhua) and climate: investigating variability in Irish Sea cod recruitment. Fish. Oceanogr,

540 23, 54-64. https://doi.org/10.1111/fog.12043 
541 Beverton, R. J. H. \& Holt, S.J. (1957). On the Dynamics of Exploited Fish Populations

542 (Fisheries Investigations, Ser. 2, Vol. 19). UK Ministry of Agriculture and Fisheries, London.

543 Britten, G. L., Dowd, M., \& Worm, B. (2016). Changing recruitment capacity in global fish

544 stocks. Proceedings of the National Academy of Sciences, 113, 134-139.

545 https://doi.org/10.1073/pnas.1504709112

546 Brunel, T., \& Boucher, J. (2006). Pattern of recruitment variability in the geographical range

547 of the exploited northeast Atlantic fish species. Journal of Sea Research, 55, 156-168.

548 https://doi.org/10.1016/j.seares.2005.07.003

549 Caddy, J. F., \& Seijo, J. C. (2005). This is more difficult than we thought! The responsibility

550 of scientists, managers and stakeholders to mitigate the unsustainability of marine fisheries.

551 Philosophical Transactions of the Royal Society B: Biological Sciences, 360, 59-75.

552 https://doi.org/10.1098/rstb.2004.1567

553 Cadigan, N. G. (2012). Fitting a non-parametric stock-recruitment model in R that is useful 554 for deriving MSY reference points and accounting for model uncertainty. ICES Journal of 555 Marine Science, 70, 56-67. https://doi.org/10.1093/icesjms/fss183

556 Clausen, L. W., Rindorf, A., Van Deurs, M., Dickey-Collas, M., \& Hintzen, N. T. (2018).

557 Shifts in North Sea forage fish productivity and potential fisheries yield. Journal of Applied 558 Ecology, 55, 1092-1101. https://doi.org/10.1111/1365-2664.13038

559 Deroba, J. J., \& Bence, J. R. (2008). A review of harvest policies: understanding relative

560 performance of control rules. Fisheries Research, 94, 210-223.

561 https://doi.org/10.1016/j.fishres.2008.01.003

562 Foley, M. M., Martone, recruitment. G., Fox, M. D., Kappel, C. V., Mease, L. A., Erickson, 563 A. L., ... Scarborough, C. (2015). Using ecological thresholds to inform resource 
management: current options and future possibilities. Frontiers in Marine Science, 2, 95. https://doi.org/10.3389/fmars.2015.00095

566 Forrest, R. E., McAllister, M. K., Dorn, M. W., Martell, S. J., \& Stanley, R. D. (2010).

567 Hierarchical Bayesian estimation of recruitment parameters and reference points for Pacific

568 rockfishes (Sebastes spp.) under alternative assumptions about the stock-recruit function.

569 Canadian Journal of Fisheries and Aquatic Sciences, 67, 1611-1634.

570 https://doi.org/10.1139/F10-077

571 Gjøsæter, H., Bogstad, B., Tjelmeland, S., \& Subbey, S. (2015). A retrospective evaluation of

572 the Barents Sea capelin management advice. Marine Biology Research, 11, 135-143.

573 https://doi.org/10.1080/17451000.2014.928414

574 Haltuch, M. A., Punt, A. E., \& Dorn, M. W. (2008). Evaluating alternative estimators of

575 fishery management reference points. Fisheries Research, 94, 290-303.

576 https://doi.org/10.1016/j.fishres.2008.01.008

577 Hobday, A. J., Spillman, C. M., Paige Eveson, J., \& Hartog, J. R. (2016). Seasonal

578 forecasting for decision support in marine fisheries and aquaculture. Fisheries Oceanography, 579 25, 45-56. https://doi.org/10.1111/fog.12083

580 ICES (2014). Report of the Joint ICES-MYFISH Workshop to consider the basis for FMSY 581 ranges for all stocks (WKMSYREF3). ICES CM 2014/ACOM:64.

582 ICES (2017). ICES fisheries management reference points for category 1 and 2 stocks. ICES

583 Advice Technical Guidelines, ICES Advice 2017, Book 12. DOI: 10.17895/ices.pub.3036.

585 Katsukawa, T. (2004). Numerical investigation of the optimal control rule for decision586 making in fisheries management. Fisheries science, 70, 123-131. 
587 Lindegren, M., \& Eero, M. (2013). Threshold-dependent climate effects limit recruitment and 588 recovery of the Kattegat cod. Marine Ecology-Progress Series, 490, 223-232.

589 https://doi.org/10.3354/meps 10437

590 Lindegren, M., \& D. M. Checkley, Jr. (2013). Temperature dependence of Pacific sardine

591 (Sardinops sagax) recruitment in the California Current revisited and revised. Canadian

592 Journal of Fisheries and Aquatic Sciences, 52, 566-577. https://doi.org/10.1139/cjfas-2012-

$593 \quad 0211$

594 Lindegren, M., Van Deurs, M., Mackenzie, B. R., Clausen, W. L., Christensen, A., \&

595 Rindorf, A. (2017). Productivity and recovery of forage fish under climate change and

596 fishing: North Sea sandeel as a case study. Fisheries Oceanography, 27, 212-

597 221.https://doi.org/10.1111/fog.12246

598 Mace, P. M., \& Doonan, I. J. (1988). A generalised bioeconomic simulation model for fish

599 population dynamics. MAFFish, NZ Ministry of Agriculture and Fisheries.

600 Mace, P. M. (1994). Relationships between common biological reference points used as

601 thresholds and targets of fisheries management strategies. Canadian Journal of Fisheries and

602 Aquatic Sciences, 51, 110-122. https://doi.org/10.1139/f94-013

603 MacKenzie B. R., \& Köster F. W. (2004). Fish production and climate: Sprat in the Baltic

604 Sea. Ecology, 85, 784-794. https://doi.org/10.1890/02-0780

605 MacKenzie, B. R., Meier, H. E. M., Lindegren, M., Neuenfeldt, S., Eero, M., Blenckner, T.,

606 Tomczak, M.T., \& Niiranen, S. (2012). Impact of climate change on fish population

607 dynamics in the Baltic Sea: A dynamical downscaling investigation. Ambio, 41, 626-636. 
608 Mangel, M., MacCall, A. D., Brodziak, J. K., Dick, E. J., Forrest, R. E., Pourzand, R., \&

609 Ralston, S. (2013). A Perspective on Steepness, Reference Points, and Stock Assessment.

610 Can. J. Fish. Aquat. Sci. 70, 930-940. https://doi.org/10.1139/cjfas-2012-0372

611 Myers, R. A., Rosenberg, A. A., Mace, P. M., Barrowman, N., \& Restrepo, V. R. (1994). In

612 search of thresholds for recruitment overfishing. ICES Journal of Marine Science, 51, 191-

613 205. https://doi.org/10.1006/jmsc.1994.1020

614 Myers, R. A. (1998). When do environment-recruitment correlations work? Reviews in Fish

615 Biology and Fisheries, 8, 285-305.

616 Myers, R. A., Bowen, K. G., \& Barrowman, N. J. (1999). Maximum reproductive rate of fish

617 at low population sizes. Canadian Journal of Fisheries and Aquatic Sciences, 56, 2404-2419.

618 https://doi.org/10.1139/f99-201

619 Nakatsuka, S., Ishida, Y., Fukuda, H., \& Akita, T. (2017). A limit reference point to prevent 620 recruitment overfishing of Pacific bluefin tuna. Marine Policy, 78, 107-113.

621 https://doi.org/10.1016/j.marpol.2017.01.017

622 Payne, M. R., Hobday, A. J., MacKenzie, B. R., \& Tommasi, D. (2019). Seasonal-to-decadal 623 prediction of marine ecosystems: Opportunities, approaches, and applications. Frontiers in 624 Marine Science, 6, 100. https://doi.org/10.3389/fmars.2019.00100

625 Pikitch, E., Boersma, P.D., Boyd, I.L., Conover, D.O., Cury, P., Essington, T., Heppell, S.S., 626 Houde, E.D., Mangel, M., Pauly, D., Plagányi, É., Sainsbury, K., \& Steneck, R.S. (2012).

627 Little fish, big impact: Managing a crucial link in ocean food webs. Lenfest Ocean Program.

628 Washington, DC. 108 pp. https://www.lenfestocean.org/-

629 /media/assets/extranets/lenfest/len_little_fish_big_impact.pdf 
630 Pikitch, E. K. (2015). Stop-loss order for forage fish fisheries. Proceedings of the National

631 Academy of Sciences, 112, 6529-6530. https://doi.org/10.1073/pnas.1505403112

632 Ricard, D., Minto, C., Jensen, O. P., \& Baum, J. K. (2012). Evaluating the knowledge base 633 and status of commercially exploited marine species with the RAM Legacy Stock

634 Assessment Database. Fish and Fisheries, 13, 380-398. https://doi.org/10.1111/j.1467$635 \quad 2979.2011 .00435 . x$

636 Rice, J. C. (2005). Implementation of the ecosystem approach to fisheries management637 asynchronous co-evolution at the interface between science and policy. Marine Ecology 638 Progress Series, 300, 265-270.

639 Ricker, W. E. (1954). Stock and recruitment. Journal of the Fisheries Board of Canada, 11, $640 \quad 559-623$.

641 Rindorf, A., Cardinale, M., Shephard, S., De Oliveira, J. A., Hjorleifsson, E., Kempf, A., ... \& 642 Simmonds, J. (2017). Fishing for MSY: using "pretty good yield" ranges without impairing 643 recruitment. ICES Journal of Marine Science, 74, 525-534.

644 https://doi.org/10.1093/icesjms/fsw111

645 Sissenwine, M. P., \& Shepherd, J. G. (1987). An alternative perspective on recruitment 646 overfishing and biological reference points. Canadian Journal of Fisheries and Aquatic 647 Sciences, 44, 913-918. https://doi.org/10.1139/f87-110

648 Sparrevohn C., Lindegren M., \& MacKenzie B. R. (2013). Climatic induced response of 649 commercially important flatfish species during the 20th century. Fisheries Oceanography, 22, 650 400-408. https://doi.org/10.1111/fog.12030 
651 Subbey, S., Devine, J. A., Schaarschmidt, U., \& Nash, R. D. (2014). Modelling and

652 forecasting stock-recruitment: current and future perspectives. ICES Journal of Marine

653 Science, 71, 2307-2322. https://doi.org/10.1093/icesjms/fsu148

654 Szuwalski, C. S., Vert-Pre, K. A., Punt, A. E., Branch, T. A., \& Hilborn, R. (2015).

655 Examining common assumptions about recruitment: a meta-analysis of recruitment dynamics 656 for worldwide marine fisheries. Fish and Fisheries, 16, 633-648.

657 https://doi.org/10.1111/faf.12083

658 Szuwalski, C. S., Britten, G. L., Licandeo, R., Amoroso, R. O., Hilborn, R., \& Walters, C. 659 (2019). Global forage fish recruitment dynamics: A comparison of methods, time-variation, 660 and reverse causality. Fisheries Research, 214, 56-64. https://doi.org/10.1111/faf.12083

661 Tommasi, D., Stock, C. A., Hobday, A. J., Methot, R., Kaplan, I. C., Eveson, J. P., ... \& 662 Pershing, A. (2017). Managing living marine resources in a dynamic environment: the role of 663 seasonal to decadal climate forecasts. Progress in Oceanography, 152, 15-49.

664 https://doi.org/10.1016/j.pocean.2016.12.011 Zhou, S. (2007). Discriminating alternative 665 stock-recruitment models and evaluating uncertainty in model structure. Fisheries Research, 666 86, 268-279. https://doi.org/10.1016/j.fishres.2007.06.026

667 Zhou, S., Yin, S., Thorson, J. T., Smith, A. D., \& Fuller, M. (2012). Linking fishing mortality 668 reference points to life history traits: an empirical study. Canadian Journal of Fisheries and 669 Aquatic Sciences, 69, 1292-1301. https://doi.org/10.1139/f2012-060

670 


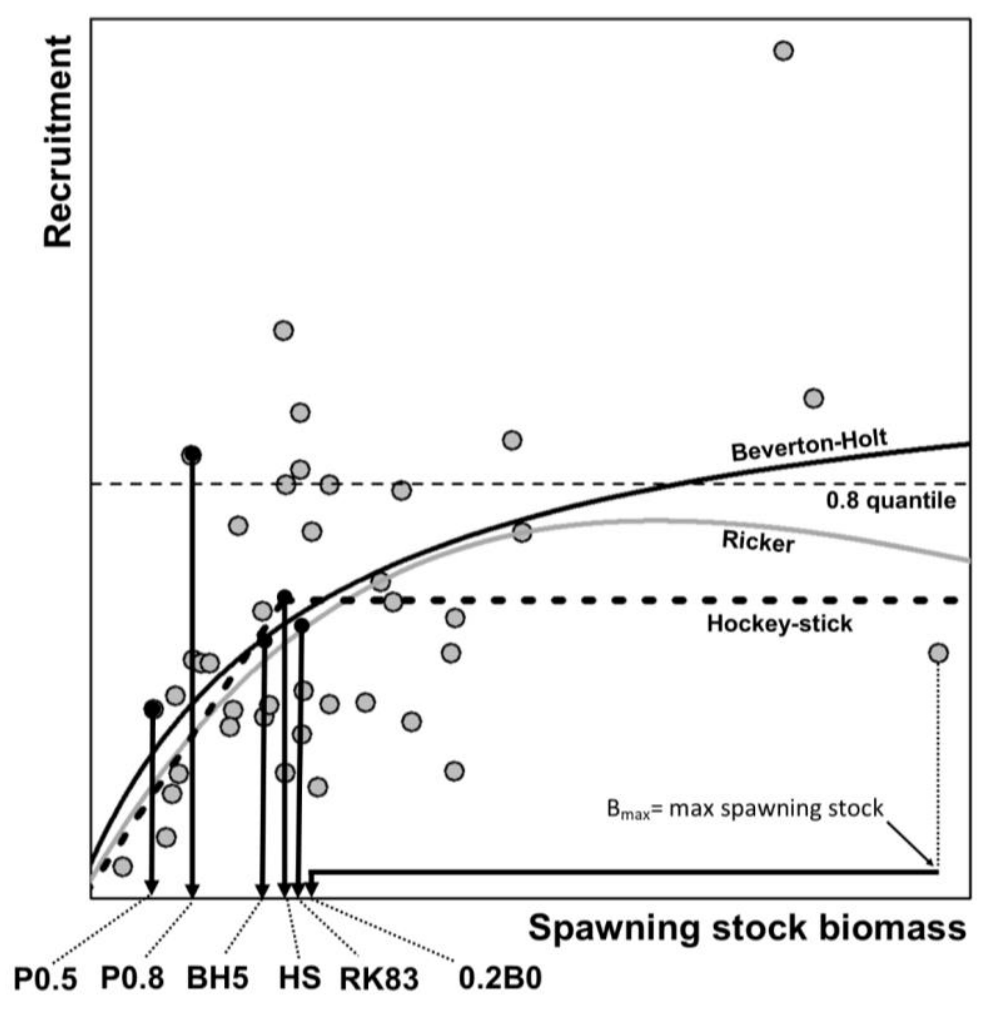

671

672 Figure 1. Illustration of different methods (P0.5, P0.8, HS, RK83, BH51, 0.2B max $_{\text {ax }}$ ) for

673 estimating biomass thresholds (BTs). Hockey stick (black dotted), Ricker (grey), and

674 Beverton-Holt (black) curves fitted to SR data from a hypothetical stock (grey dots). The

675 dashed horizontal line represents the 0.8 quantile of recruitment and the maximum spawning

676 stock biomass $\left(\mathrm{B}_{\max }\right)$ used in $0.2 \mathrm{~B}_{\max }$ approach is indicated by a bended arrow. The vertical

677 arrows point to the spawning stock biomasses representing the BT derived from each of the

678 methods.

679

680 


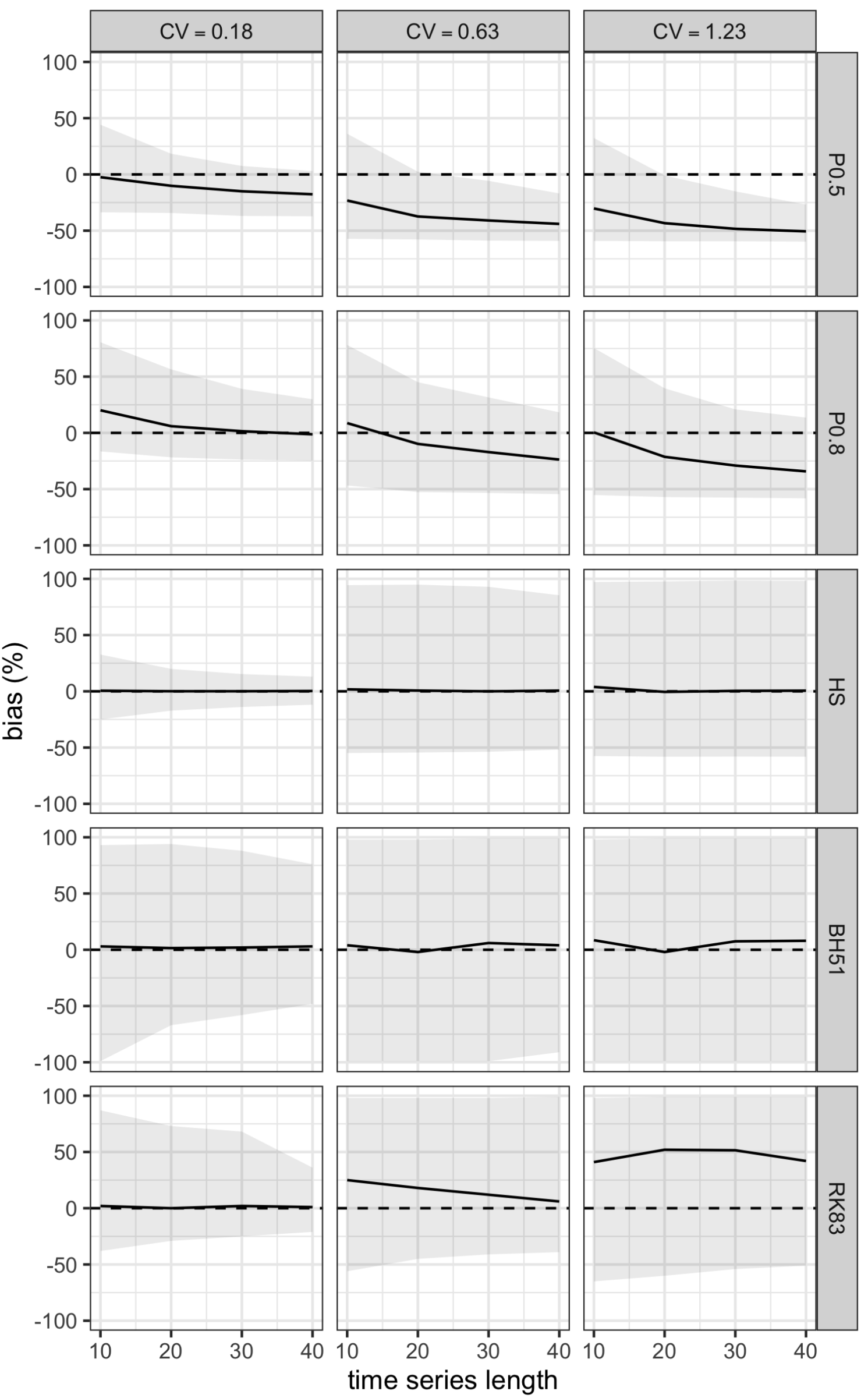


682 Figure 2. Biomass thresholds (BTs) in simulations. Each column of panels used a different 683 coefficient of variation $(\mathrm{CV})$ in recruitment in the simulated stock-recruitment data.

684 Horizontal dashed lines represent $0 \%$ bias from the simulated threshold (i.e. the breakpoint of 685 the underlying hockey stick from which data were simulated). Solid lines are the medians of 6861000 replicates and the grey areas encompass the 0.025 and 0.975 quantiles. The $\mathrm{x}$-axis 687 represents time-series lengths used to estimate each BT. Five different methods were used to 688 calculate BT (from top and down: P0.5, P0.8, HS, BH51, and RK83).

689

690

691 

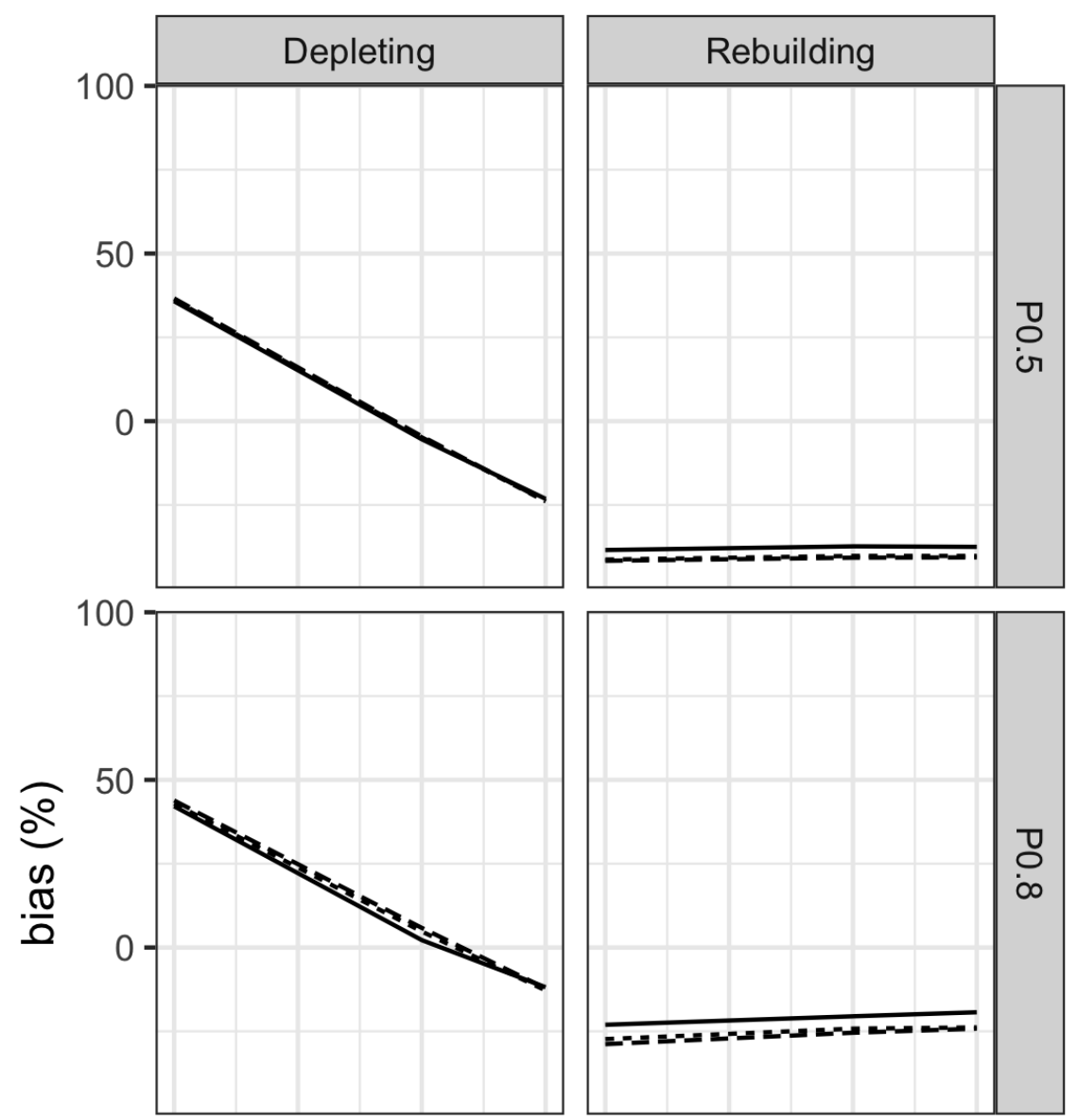

shape

- hockey

.... Ricker

- - . BevertonHolt

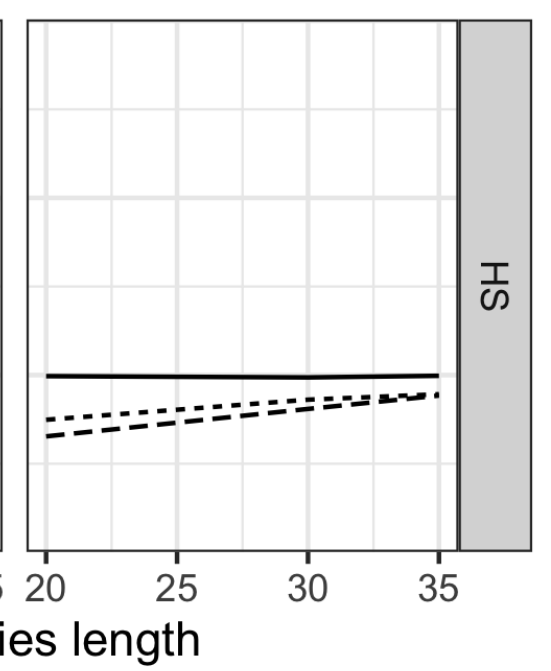

693 Figure 3. The effect of stock development on biomass thresholds (BTs). Median bias (relative

694 to the simulated threshold) in each BT is shown for combinations of: (i) three different

695 methods for estimating BT (rows of panels), (ii) different underlying stock-recruitment

696 relationships (hockey stick (solid line), Ricker (dotted line), and Beverton-Holt (dashed 
697 line)), (iii) different time-series lengths (x-axis), and (iv) depleting and rebuilding stocks

698 (columns of panels).

699

700

701
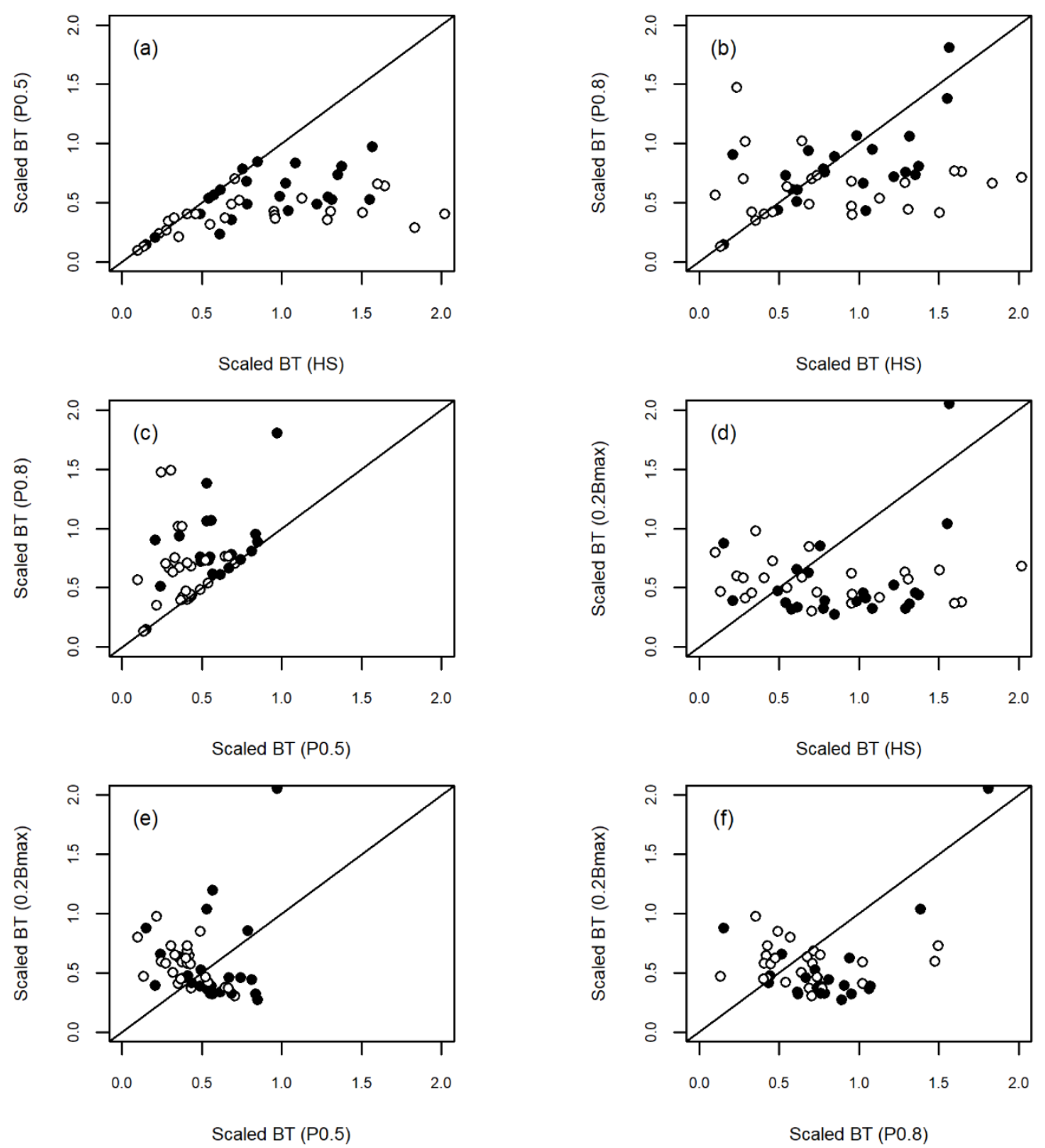

703 Figure 4. Comparison of biomass thresholds (BTs) of 51 small-bodied pelagic stocks (scaled

704 to the geometric mean spawning stock biomass) and calculated using three different methods

705 (P0.5, P0.8, HS, 0.2B $\mathrm{B}_{\max }$, respectively). BTs calculated using HS were divided into stocks 
708 Hence, outlier values twice the geometric mean spawning stock biomass were not included in

709 the plots (mounting to 4, 5, 0, 5, 1, 3 data points in a, b, c, d, e, f, respectively).
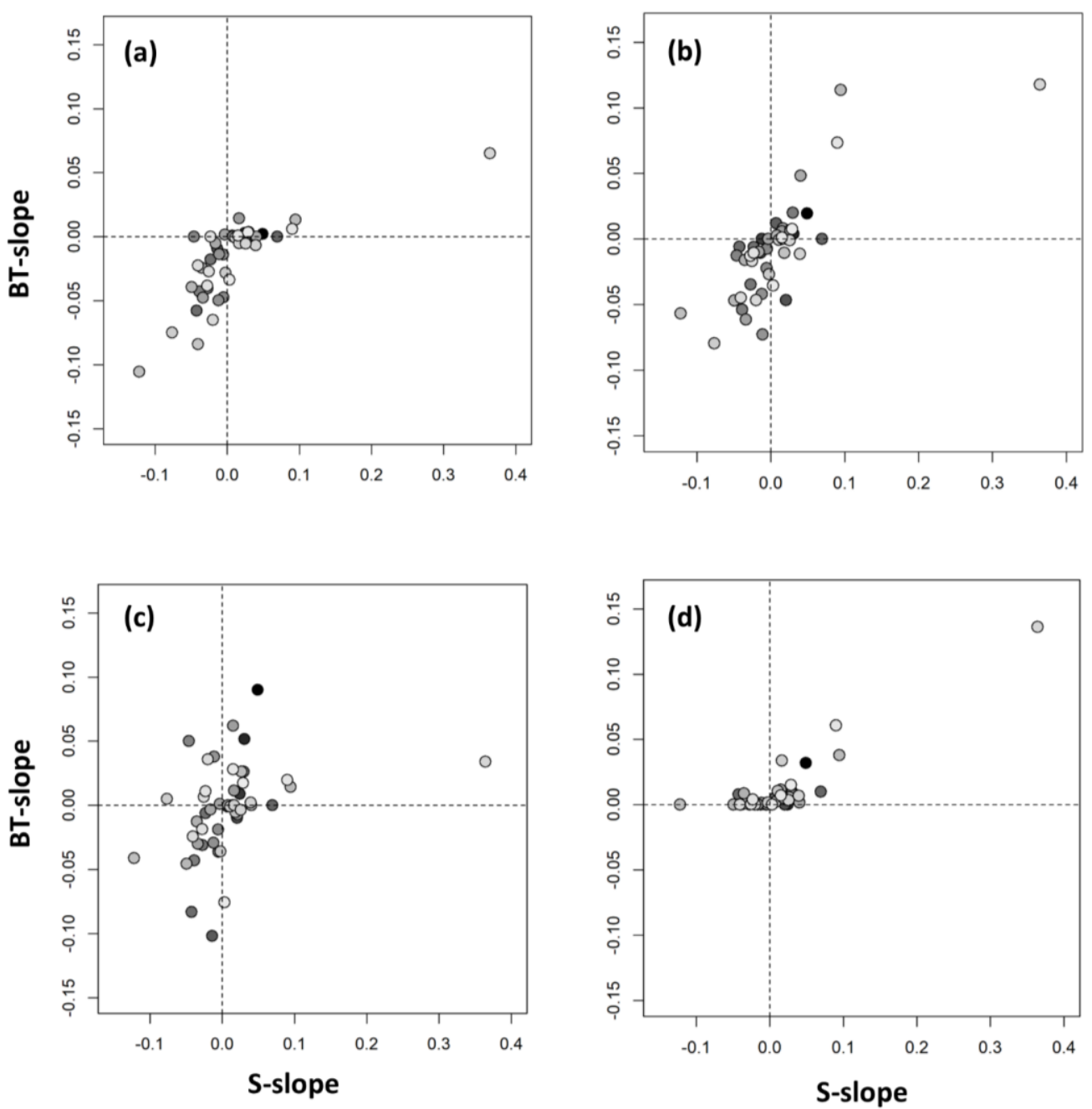

712

713 Figure 5. The effect of stock development. Two types of slopes were calculated for each of

714 the 51 stocks: (i) the slope describing the relationship between time-series length and biomass

715 threshold (BT-slope) and (ii) the slope of spawning stock biomass as a function time (S- 
716 slope). Rebuilding stocks have positive S-slopes and depleting stocks have negative S-slopes.

717 BT-slopes were derived using the following four methods: P0.5 (a), P0.8 (b), HS (c), 0.2B max $_{\max }$

718 (d). The grey scale represents the uncertainty of the S-slope (dark grey is high uncertainty).

719

720

721 


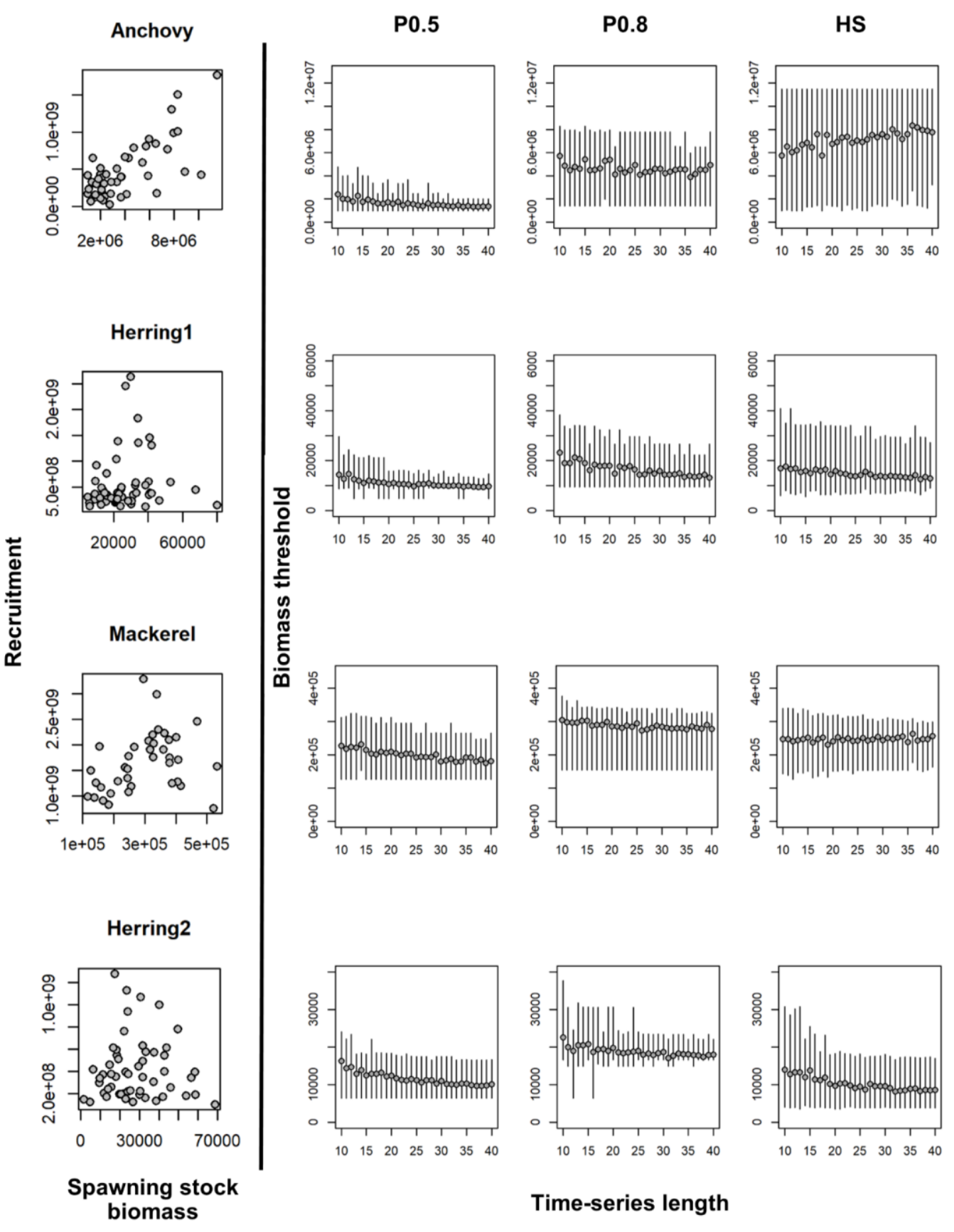

723 Figure 6. Four case-study stocks, representing different shapes of stock-recruitment

724 relationships: Peruvian anchoveta from North Central Peru (top), Pacific herring from the US

725 west coast (upper middle), chub mackerel from the Tsushima strait (lower middle), and

726 Pacific herring from the Prince Rupert district. To the left of the vertical black line, plots of

727 the SR relationship are shown. To the right of the vertical black line, mean biomass 
728 thresholds (BTs), incl. 10\% and 90\% quantiles, are shown for three different methods (P0.5, 729 P0.8, and HS) and as a function of time-series length. Quantiles were generated by randomly

730 sampling with replacement $\mathrm{n}(\mathrm{n}=10,11,12, \ldots, 40)$ pairs of spawning stock biomass and

731 recruitment with replacement 100 times.

732

733

734

735

736 